\title{
A ação espacial do turismo: análise dos atrativos e equipamentos turísticos na Serra do Cipó (MG)
}

\section{Tourism space of action: an analysis of the attractions and tourist facilities in the Serra do Cipó (MG, Brazil)}

Solano de Souza Braga, Bernardo Machado Gontijo, Leandro Martins Vieira

\begin{abstract}
RESUMO
O presente artigo pretende trazer reflexões e alternativas para 0 entendimento da ação espacial do turismo. Apesar do senso comum encarar o turismo como uma atividade reprodutora do espaço urbano (por meio da introdução de práticas como a prestação de serviços, especulação imobiliária, aculturação etc.), o que será proposto é um exercício contrário: pensar que o espaço urbano atua como produtor / reprodutor da atividade turística em espaços rurais e naturais. Considera-se, neste caso, a infraestrutura em áreas urbanizadas e semiurbanizadas como fator primordial para o desenvolvimento da atividade turística.
\end{abstract}

PALAVRAS-CHAVE: Turismo; Organização Espacial; Rural e Urbano.

\section{ABSTRACT}

This article aims to bring ideas and alternatives for understanding the tourism space of action. Despite the common sense view tourism as a reproductive activity of urban space (through the introduction of practices such as services, real estate speculation, acculturation etc.), what is proposed here is an opposite exercise: thinking that the urban space acts as producer / reproducer of the touristic activity in rural and natural spaces. The infrastructure in urbanized and semi urbanized areas is considered in this case as a key factor for the development of the touristic activity.

KEYWORDS: Tourism; Space Organization; Rural and Urban. 


\section{Apresentação}

Entre diversas questões envolvendo a geografia e o turismo, pode-se ver que ainda existem muitas lacunas sobre o entendimento da ação espacial do turismo. O grau de transformação que a atividade turística pode provocar nas relações sociais, territoriais, econômicas e culturais dos moradores de núcleos receptores. $\mathrm{E}$, ao mesmo tempo, como as estruturas locais podem influenciar o tipo de turismo que vai se estabelecer em um espaço que é também de moradia e de produção para a comunidade local.

Pretende-se defender nesse artigo a hipótese de que o turismo acontece e depende, majoritariamente, de deslocamentos entre espaços urbanizados, fato este que seria paradoxal, por exemplo, na forma como os segmentos do ecoturismo ${ }^{1}$ e o turismo rural ${ }^{2}$ são planejados e estudados no Brasil.

Foi adotada como área de experimentação metodológica municípios localizados na Bacia do Rio Cipó, localizada na Reserva da Biosfera da Serra do Espinhaço - Minas Gerais. A região foi escolhida por sofrer tanto a pressão de urbanização, como o crescimento da atividade turística em três dos segmentos mais relacionados com as questões espaciais abordadas: 0 turismo no espaço rural ${ }^{3}$, o turismo rural e o ecoturismo. Outro motivo é que existem em uma mesma região áreas muito visitadas, outras que começam a ser visitadas e áreas ainda praticamente intocadas.

Esse conjunto de seis municípios que compõem a Bacia do Rio Cipó apresenta em si uma dinâmica semelhante ao observado na região da Serra do Cipó como um todo: a) o encontro do modo de vida rural com práticas urbanas; b) a pressão de uma nova atividade; c) o turismo concorrendo e/ou se adaptando as estruturas de organização social locais.

Uma breve análise da área de estudo foi realizada na dissertação "A região da Serra do Cipó: complexidade, tempo e turismo", onde foi possível constatar o fato de que mesmo tendo homogeneidade na oferta de atrativos turísticos ${ }^{3}$, o desenvolvimento da atividade turística ocorreu de formas e em tempos diferentes ao longo da Região da Serra do Cipó.

Apesar de ser muito comum a afirmação de que a motivação para a maioria das viagens é a vivência de conhecer novas paisagens e novas culturas, grande parte dos deslocamentos turísticos ocorre entre áreas urbanizadas. Mesmo no ecoturismo, as regiões com infraestrutura mais completa tendo pousadas, restaurantes e acessos pavimentados tornam as áreas muito mais visitadas em relação a regiões onde só é possível chegar a pé ou em estradas de terra e onde a oferta de serviços é reduzida ou nula. Sendo isso mais importante do que qualidade dos atrativos naturais e/ou culturais.

Nesse quadro, surgem os questionamentos que nortearão a pesquisa e possibilitará a comprovação da hipótese, o primeiro seria "o porquê de alguns lugares serem visitados por turistas e outros não", o segundo "o que faz o turismo se desenvolver e ser mais percebido em algumas regiões que em outras" e, por fim "qual a relação que existe entre a localização dos atrativos turísticos e as infraestruturas urbanas". 


\section{Caracterização da área de estudo}

A Serra do Cipó foi considerada como uma região composta por vários elementos marcantes e formadores de sua identidade. Dentro da soma de critérios adotados e representados abaixo, destacamos a descrição dos elementos utilizados como parâmetros de análise, mas ressaltamos, em concordância com GONDOLO (1999), o fato de que um elemento não é consequência do outro. Não há relação de causalidade explícita, são elementos avulsos, o que não elimina certas conexões, pois existem vínculos entre eles. Partindo desse pressuposto, os elementos são (Figura 1):

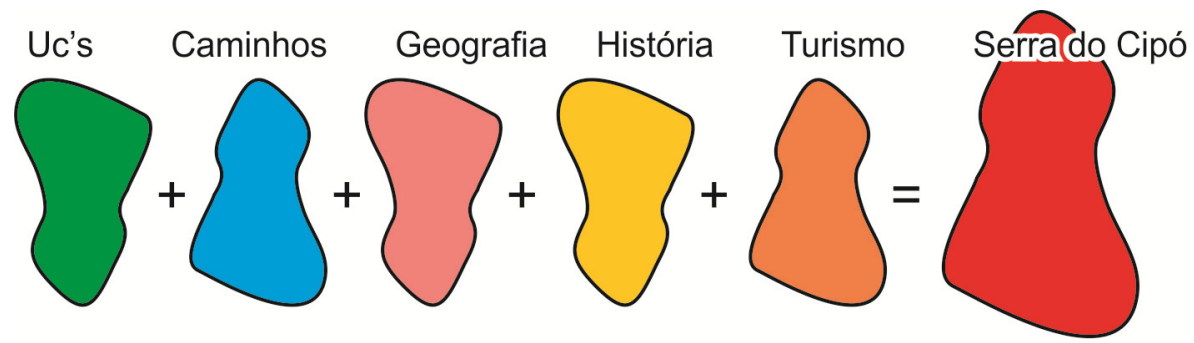

Figura 1: Critérios utilizados para delinear a Serra do Cipó. Fonte: Braga (2011, p.24).

Figure 1: Criteria used to delineate the Serra do Cipo. Source: Braga (2011, p.24).

As UC's ${ }^{5}$ têm grande importância além de ter o Parque Nacional da Serra do Cipó como um dos principais ícones regionais, a existência de outras Unidades de Conservação como a Reserva da Biosfera da Serra do Espinhaço, a criação do Mosaico Cipó-Intendente e a expectativa de ampliação do PARNA indicam que a relação população $\mathrm{x}$ poder público $\mathrm{e}$ áreas protegidas ditarão o ritmo do desenvolvimento local. Na Serra do Cipó as Unidades de Conservação, por falta de infraestrutura e dificuldade de acesso, não são os pontos mais visitados da região.

Os "caminhos" abordarão a importância dos eixos de penetração que levaram para a região os primeiros ameríndios, os bandeirantes, os quilombolas, sesmeiros, e várias personalidades e cientistas que nos caminhos da serra construíram grande parte do conhecimento sobre o Brasil e Minas Gerais no período Imperial ao longo da Estrada Real.

A "geografia" destacará desde a formação física da Serra do Espinhaço, até a posição privilegiada que faz com que encontremos diversidades que vão de biomas (Mata Atlântica, Cerrado e Campos Rupestres), bacias hidrográficas (Bacias do Rio São Francisco à oeste, do Rio Doce à leste e do Rio Jequitinhonha ao norte). Considerando os aspectos físicos, a Serra do Cipó é um dos vários nomes locais recebidos pela Serra do Espinhaço (também conhecida como Serra Geral) ao longo dos seus $1.200 \mathrm{~km}$ entre o Quadrilátero Ferrífero, em Minas Gerais, até a Chapada Diamantina, na Bahia. Lá também é onde espacialmente as "Minas" (formada pelo bioma da Mata Atlântica e relevo ondulado) se encontram com os "Geraes" (localizado no bioma Cerrado e de relevo plano). 
O componente "história" destaca-se a grande importância que esta região de passagem do período Colonial e Imperial teve quando ligava duas das mais (senão as mais) ricas cidades das Américas.

O turismo vem como último e grande fator de transformação e descobrimento da Serra do Cipó. Veremos como Circuitos, Eixos Turísticos, estão se desenvolvendo e convivendo com a realidade regional.
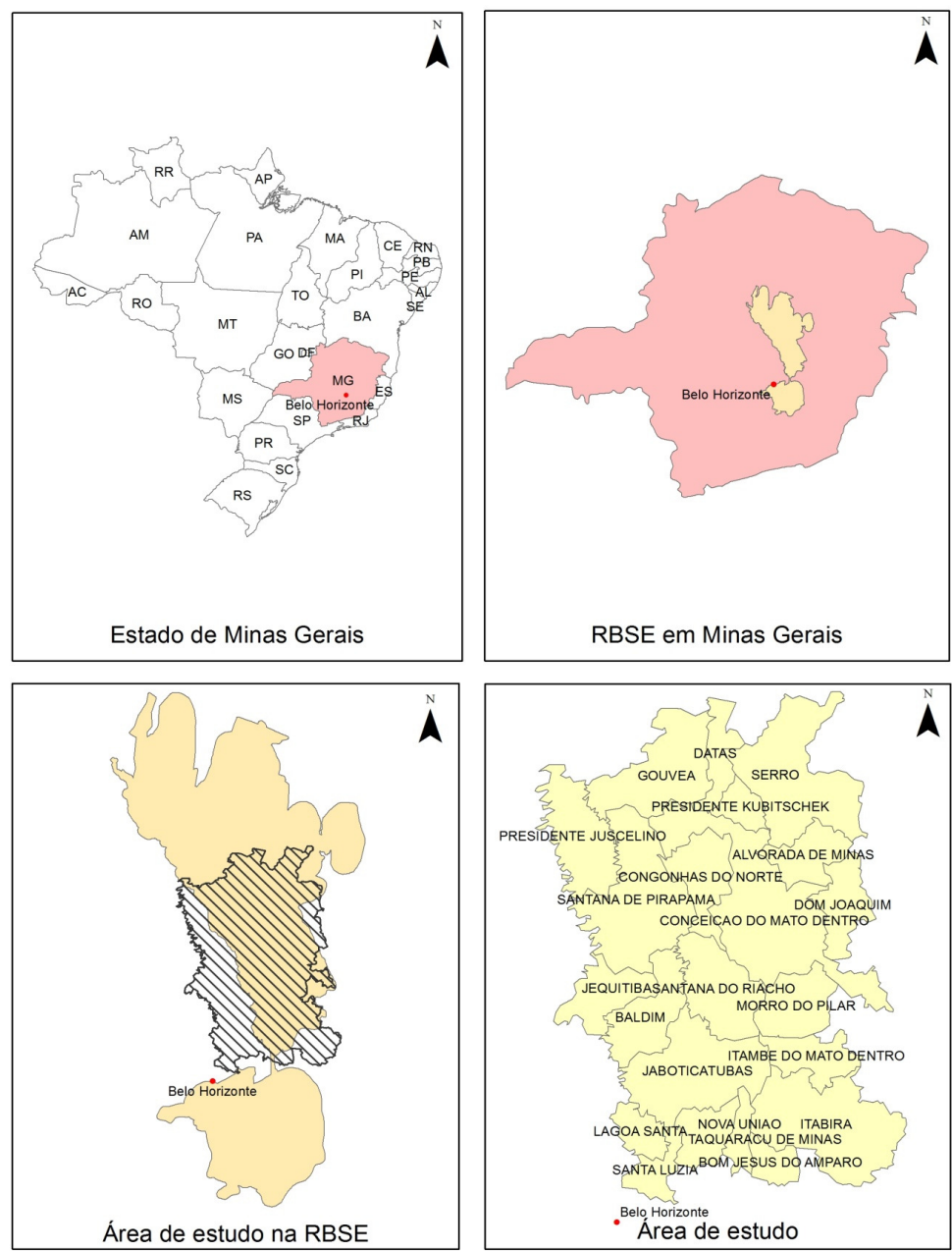

Figura 2: Localização da área de estudo. Fonte: (BRAGA; KNEGT, 2011).

Figure 2: Location of the study area. Source: (BRAGA and KNEGT, 2011).

\section{A Serra do Cipó e o Turismo}

Falar sobre o Turismo na Serra do Cipó é abordar assuntos como a transformação das paisagens em atrativos turísticos, de relações pessoais em prestação de serviços e territorialidades e espaços criados a partir da interação de turistas e moradores. Será possível ver como o turismo contribui para a ideia de região que se faz na Serra, os fatores de atração turística e quais tipos de turismo ocorrem.

A Serra do Cipó não perdeu ao longo de todos estes anos o magnetismo sobre os viajantes, sendo hoje um destino muito conhecido dos turistas e ecoturistas em todo Brasil. Ela apresenta diversas histórias e 
possui marcas nas paisagens e nas pessoas que ilustram os efeitos do fenômeno turístico em áreas naturais. Através da bandeira do ecoturismo, ou "turismo verde", a modernidade vem chegando para povoados, vilas e fazendas da região e mudando o ritmo e modo de vida dos moradores da Serra. Esse fato é bem ilustrado por Soares (2005), ao citar palavras o Sr. José Belizário "O lugar passou a ter seu ritmo de vida ditado por quem vem de passagem. E, para estes, a Serra, por mais maravilhosa, não passa de um cenário das férias ou do fim de semana" (1995, p.12).

Uma breve análise sobre a relação existente entre os atrativos turísticos e a infraestrutura será realizada com base no Diagnóstico de Turismo de Natureza - Destino Serra do Cipó - Estrada Real, Minas Gerais, Brasil, EPLERWOOD (2007) em relação ao qual faremos comparações e análise entre os dados desse estudo e do INVTUR. Apesar de escalas regionais e metodologias diferentes, é possível extrair dados para subsidiar a ação e percepção espacial do turismo da região da Serra do Cipó. O estudo citado trouxe a seguinte classificação (vista no mapa 01) para as áreas onde ocorre visitação: Áreas de uso intensivo (Frontcountry 01) ${ }^{7}$ (7); 2. Áreas de uso extensivo (Frontcountry 02); Áreas de uso restrito (Backcountry 01) $^{9}$ e Áreas remotas (Backcountry 02) ${ }^{10}$.

Outro fator importante para interpretar estes dados é que foram listados só atrativos turísticos que recebem fluxo considerável de visitação, sendo que recursos com potencial para se tornar atrativo não foram listados. Ao comparar-se os mapas 1 e 2, pode-se perceber uma diferença substancial no número de atrativos, ora pela inserção de novas áreas, ora pelo critério utilizado que tentou relacionar todos os atrativos dos municípios, não só os mais visitados. Fica evidente, ao comparar os mapas citados, que as áreas menos visitadas e com menos estrutura correspondem aos topos de Serra, que são os locais de acesso mais difícil e que estão mais inseridos em UC's

Este mesmo estudo (EPLERWOOD, 2007) concluiu que o turismo que acontece na Serra do Cipó é basicamente "motivado" pelas cachoeiras e rios, mas que é a existência e qualidade de infraestrutura e as formas de acesso que definem quais são os atrativos mais visitados, como pode-se observar nas Figuras 3 e 4. Logo, isso se reflete nas áreas que são mais visitadas na Serra do Cipó, processo que está de acordo com o que afirma Teles (2006, p.12) sobre os efeitos espaciais da atividade turística:

Desse modo pode-se dizer que o crescimento de alguns setores como o de hospedagens, alimentos e bebidas e transportes, junto à consolidação e a formação de uma classe consumidora de produtos turísticos, deu origem a diferentes fluxos, resultando em uma nova ordem no processo de ocupação do espaço, observando que cada vez há menos território sem turistas. 


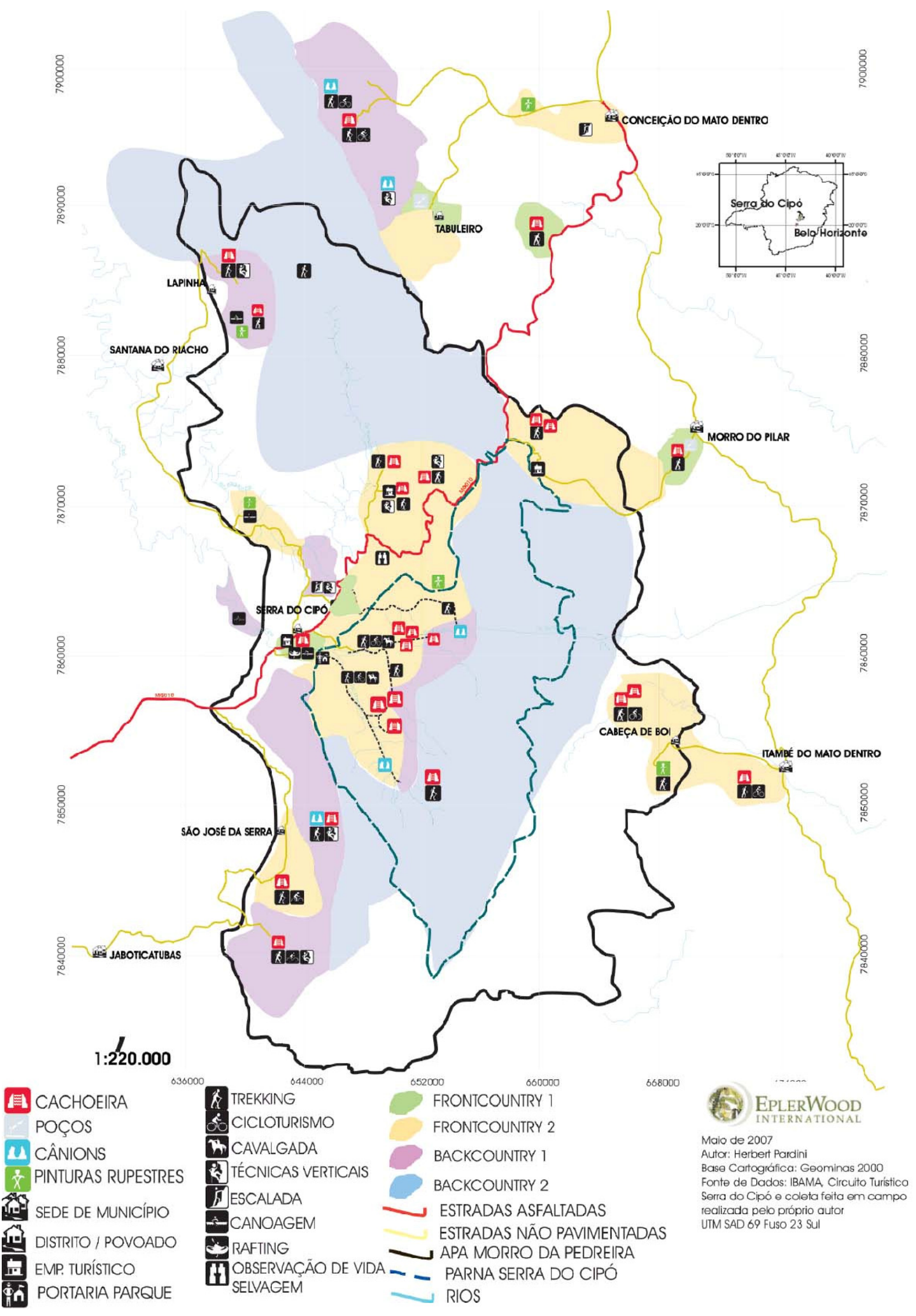

Figura 3: Áreas de uso turístico Região da Serra do Cipó. Fonte: EplerWood (2007, p.35).

Figure 3: Areas of use tourist region of Serra do Cipó. Source: EplerWood (2007, p.35) 


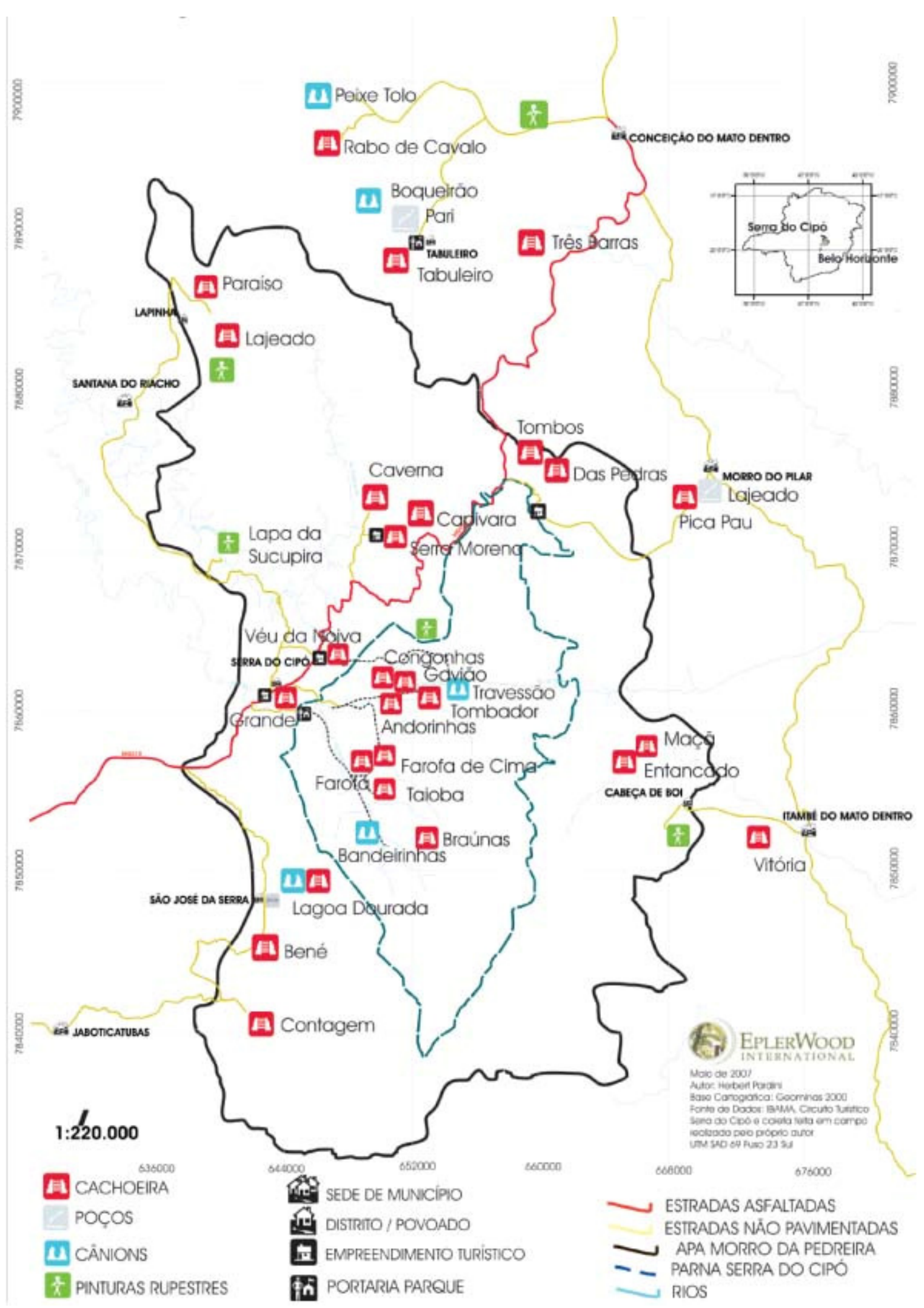

Figura 4: Distribuição de atrativos na região da Serra do Cipó. Fonte: EplerWood (2007, p.22). Figure 4: Distribution of attractions in the Serra do Cipó region. Source: EplerWood (2007, p.22). 
A questão aqui não é se a infraestrutura foi instalada porque o atrativo recebia visitação, mas sim que é essa mesma infraestrutura um fator determinante para o atrativo receber poucos ou muitos visitantes. Exemplos como a Cachoeira da Capivara (Santana do Riacho), as cachoeiras dos Inhames e do Rio Preto em Santana de Pirapama e as várias em Nova União podem ser citados como atrativos que recebiam muita visitação e hoje, ou estão fechados, ou permanecem sem infraestrutura, não tirando proveito da demanda existente.

Outro fato bem ilustrado através da leitura dos mapas é que a homogeneidade na existência de atrativos naturais em todos os municípios contrasta com a pequena e concentrada região onde a visitação turística é mais intensa. Isso nos leva ao mesmo questionamento de Gomes (2002, p.172): "É justamente a interpretação dessa lógica do arranjo espacial e de seus sentidos que compõe o campo fundamental das questões geográficas: Porque as coisas estão dispostas no espaço dessa maneira? Qual [é] o significado e as consequências de tal ordem espacial?".

Essas questões podem começar a ser respondidas ao observarmos que, nos mapas a disposição dos atrativos mais visitados e as áreas de uso intensivo estão próximas a vias de acessos pavimentadas ou vias não pavimentadas em bom estado de conservação. Elas também estão localizadas em distritos ou povoados que possuem concentração de atrativos muito próximos entre si.

Outro fato que chama a atenção é que as "Áreas remotas (Backcountry 02 ou Wilderness)" estão localizadas em UC's de proteção integral, onde existe pouca ou nenhuma infraestrutura. O PARNA Cipó e o Parque Estadual Serra do Intendente carecem de sinalização, mais portarias (no caso do PARNA Cipó, apesar do plano de manejo sugerir 5 portarias, atualmente só possui duas), trilhas estruturadas, serviços de alimentação e isso se reflete espacialmente ao se analisar por onde os turistas transitam dentro da região da Serra do Cipó. Percebemos que existe ainda um grande "potencial turístico" em toda a região, destacadamente o interior pouco explorado das UC's. Neste sentido, vale lembrar o que MAGALHÃES (2000, p.183) define como potencial turístico "o conjunto dos diversos bens naturais e artificiais que a localidade possui como base da atividade turística. Podem ser transformados em recursos passiveis de serem utilizados pela atividade turística".

A autora completa afirmando que o potencial turístico pode ser divido entre Potencial Natural e Potencial Artificial. Como já foi exposto nos mapas e na caracterização dos municípios, o potencial natural é o grande motivador do turismo na região. Esse potencial foi definido por Magalhães (2000, p.183) como:

O potencial natural: é a matéria prima da oferta turística e compõe-se daquilo cuja criação não houve interferência humana direta ou indireta. É um dos fatores primordiais para que uma localidade, uma região ou um país seja considerado possuidor da vocação turística. Caracteriza-se pela posse de alguns dos seguintes elementos da natureza: o clima, a configuração geográfica e as paisagens, os 
elementos silvestres ou de vegetação, a flora e a fauna, a água, a geologia.

Outro fator curioso é que os atrativos do PARNA Cipó são pouco visitados devido, justamente, a falta de infraestrutura e às restrições impostas pelos administradores. Atualmente, dentre as dezenas de atrativos naturais localizados no PARNA, só é possível visitar a Cachoeira da Farofa sem o auxilio de guias e/ou condutores locais.

Podemos concluir, considerando que a oferta turística é o conjunto dos atrativos, equipamentos, bens e serviços que interagem para satisfazer as necessidades dos turistas no destino, que a Serra do Cipó possui, quantitativamente, uma boa oferta turística. Mas se lembrarmos, assim como Beni (2001) que a oferta turística se divide entre oferta original ou primária e derivada ou secundária, ver-se-á as distorções que existem na Serra devido a má distribuição de equipamentos turísticos.

Sendo a oferta original relacionada aos recursos turísticos naturais, enquanto a derivada está relacionada à infraestrutura de apoio e às prestações de serviços turísticos, já vimos que existe uma má distribuição de uma em relação a outra. Nesse aspecto, pode ser feita uma breve análise quantitativa ao comparar os dois tipos de oferta. Tendo como base o INVTUR realizado pelos Circuitos Turísticos temos a seguinte distribuição da oferta original: Conceição do Mato Dentro 30 atrativos; Santana do Riacho com 12; Morro do Pilar 11; Jaboticatubas 11 e Itambé do Mato Dentro 14.

Além desses aspectos sobre a oferta original, no âmbito da oferta secundária existe a distinção entre os equipamentos gerais e os equipamentos turísticos Beni (2001): os equipamentos gerais são os elementos infraestruturais, tudo aquilo construído pelo homem para atender à procura turística, como vias de acesso, de comunicação, saneamento básico, rede de distribuição, entre outros. E, assim como em boa parte das cidades interioranas brasileiras, os das Serra do Cipó têm serviços públicos precários nessas áreas citadas.

Ao analisar os equipamentos turísticos, que são todos aqueles criados especificamente para o turismo, sendo esta sua principal finalidade, vemos se desenhar um quadro que demonstra como o turismo se reflete de formas diferentes nos municípios da Serra do Cipó. Esses equipamentos são os meios de hospedagens, restaurantes, instalações recreativas, agências de viagem, locadoras de veículos, entre outros. Nos mapas expostos neste trabalho, foram considerados apenas os equipamentos turísticos. Nesse sentido, o critério de seleção foi se os estabelecimentos prestam algum tipo de serviço turístico ou vendem para turistas produtos da região. Daí se exclui os estabelecimentos que prestam outros serviços senão os pertencentes aos incluídos no INVTUR, para efeito ilustrativo será exposto a infraestrutura de alimentação e hospedagem nos municípios para compra-las a quantidade de atrativos.

Sobre a oferta derivado, observa-se a seguinte distribuição entre os municípios: Conceição do Mato Dentro com 19 equipamentos de hospedagem e 21 de alimentação; Santana do Riacho com 63 equipamentos 
de hospedagem e 51 de alimentação; Morro do Pilar com 5 equipamentos de hospedagem e 18 de alimentação; Jaboticatubas com 21 equipamentos de hospedagem e 28 de alimentação e Itambé do Mato Dentro com 16 equipamentos de hospedagem e 18 de alimentação.

Vemos aqui como é grande a diferença entre o número de atrativos naturais e a porção destes que possuem alguma estrutura de apoio a visitação. O curioso é que a constatação da importância da estruturação básica e turística para atração de fluxo de visitantes é geralmente ignorada pelos planejadores do turismo no Brasil. Os gastos com marketing geralmente são o carro chefes dos gastos com turismo e, quando há a preocupação com obras elas não são acompanhadas de pesquisas e planejamento para se adequar as necessidades de demanda.

\section{Conclusão}

É por meio da análise da oferta de atrativos e equipamentos turísticos que foi possível, mesmo que de forma embrionário, identificar a importância que cada um tem para o desenvolvimento da atividade turística. Apesar de muito comum a suposição de que o fluxo de visitante determina o ritmo e grau de transformações nos núcleos receptores, observa-se que são as respostas do núcleo receptor que determinam a estagnação ou o desenvolvimento da atividade.

Por meio do levantamento mapeamento dos atrativos e equipamentos turísticos presentes na região do Parque Nacional da Serra do Cipó, foi possível identificar, conforme proposto nos objetivos deste trabalho que regiões com melhores infraestruturas tente a receber um fluxo maior de visitantes.

A indução do processo de transformação espacial que pode ser percebida por abertura de empreendimentos e equipamentos turísticos depende basicamente de como os moradores locais se colocam diante de uma nova atividade econômica e da circulação de pessoas estranhas ao seu entorno de moradia.

Ou seja, a existência de atrativos naturais é um fator importante de atratividade, mas sem as desejáveis condições de alojamento, transporte e alimentação tendem a transformar o local em algo pouco acessível e procurado somente por alguns segmentos dispostos a conhecer sítio, independente das dificuldades e inacessibilidade do entorno.

\section{Referências bibliográficas}

BENI, M.C. Análise estrutural do turismo. 2. ed. São Paulo: Ed. SENAC, 2001

BRAGA, S.S.; GONTIJO, B.M. O turismo como vetor de transformações sócio-espaciais: uma análise complexa das três sub-regiões da Serra do Cipó - MG. XIII SBGFA - Simpósio Brasileiro de Geografia física Aplicada, Viçosa. Anais do XIII SBGFA - a Geografia física e as dinâmicas de apropriação da natureza, 2009, p.1-6. 
BRAGA, S.S. Serra do Cipó: a complexidade de uma região moldada pelo tempo, turismo e geografia. Dissertação (mestrado) - Universidade Federal de Minas Gerais, Instituto de Geociências, 2011.

EPLERWOOD INTERNATIONAL. Diagnóstico de Turismo de Natureza Destino Serra do Cipó - Estrada Real, Minas Gerais, Brasil (2007).

IBGE - Instituto Brasileiro de Geografia e Estatística. Contagem de população. Sistema de recuperação de informação municipal - Censo Demográfico. Rio de Janeiro, IBGE, 1996.

IEF/MG - Instituto Estadual de Florestas de Minas Gerais. Sítio eletrônico: www.ief.mg.gov.br. Visitado em: 10/12/2010.

GARDNER, G. Viagem ao Interior do Brasil. Belo Horizonte: Itatiaia, 1975.

GOMES, P.C.C. A condição urbana: ensaios de geopolítica da cidade. Rio de Janeiro: Bertrand, 2012.

GONDOLO, G.C.F. Desafios em um sistema complexo à gestão ambiental: Bacia do Guarapiranga, região metropolitana de São Paulo. FAPESP e ANNABLUME Editora, São Paulo, SP, 1999.

MAGALHÃES, J.C. Emancipação político-administrativa de municípios no Brasil. Departamento de Estudos Regionais e Urbanos (Dirur) do Instituto de Pesquisa Econômica Aplicada (Ipea), 2001.

MAGALHÃES, C.F. A organização do Espaço turístico de municípios mineiros: Uma proposta metodológica. Dissertação de mestrado, IGCUFMG, 2000.

MAGALHÃES, C.F. Diretrizes para o turismo sustentável em municípios, São Paulo: Roca, 2002.

MINISTÉRIO DO TURISMO DO BRASIL. Secretaria Nacional de Políticas de Turismo, Departamento de Estruturação, Articulação e Ordenamento Turístico, Coordenação Geral de Segmentação. Marcos conceituais. Brasília, 2006.

MINISTÉRIO DO TURISMO DO BRASIL Secretaria Nacional de Políticas de Turismo, Departamento de Estruturação, Articulação e Ordenamento Turístico, Coordenação Geral de Segmentação. Turismo rural: orientações básicas. Brasília, 2008a.

MINISTÉRIO DO TURISMO DO BRASIL Secretaria Nacional de Políticas de Turismo, Departamento de Estruturação, Articulação e Ordenamento Turístico, Coordenação Geral de Segmentação. Diretrizes para o desenvolvimento do Turismo rural no Brasil. Brasília, 2008b.

MINISTÉRIO DO TURISMO DO BRASIL Secretaria Nacional de Políticas de Turismo, Departamento de Estruturação, Articulação e Ordenamento Turístico, Coordenação Geral de Segmentação. Ecoturismo: orientações básicas. Brasília, 2008c.

RODRIGUES, A.B. Turismo: impactos socioambientais. São Apulo, Hucitec, 1999. 
TELES, R.M.S. A importância do território na prática do planejamento turístico - reflexões acerca do Brasil. In: RUSCHMANN, D.V.M.; SOLHA, K.T. (orgs.). Planejamento Turístico. Barueri: Manole, 2006.

VASCONCELLOS, M.J.E. Pensamento sistêmico: O novo paradigma da ciência. Campinas: Papirus, 2002.

\section{Notas:}

1 O Ecoturismo é um segmento da atividade turística que utiliza, de forma sustentável, o patrimônio natural e cultural, incentiva sua conservação e busca a formação de uma consciência ambientalista por meio da interpretação do ambiente, promovendo o bem-estar das populações. MINISTÉRIO DO TURISMO (2006, p.9).

2 Turismo Rural é um conjunto de atividades turísticas desenvolvidas no meio rural, comprometido com a produção agropecuária, agregando valor a produtos $\mathrm{e}$ serviços, resgatando e promovendo o patrimônio cultural e natural da comunidade. MINISTÉRIO DO TURISMO DO BRASIL (2008:49).

${ }^{3}$ Todas as atividades praticadas no meio não urbano, que consiste de atividades de lazer no meio rural em várias modalidades definidas com base na oferta: Turismo Rural, Turismo Ecológico ou Ecoturismo, Turismo de Aventura, Turismo de Negócios, Turismo de Saúde, Turismo Cultural, Turismo Esportivo, atividades estas que se complementam ou não. MINISTÉRIO DO TURISMO DO BRASIL (2008:19).

${ }^{4}$ Devido a política estadual de implantação do ICMS Turístico, todos os municípios citados e que queiram receber o repasse de verbas do Estado são obrigados a manterem, dentre outros requisitos, atualizados inventários de oferta de serviços e atrativos turísticos. Sendo assim, já existem dados e georreferenciados de grande parte das estruturas relacionadas a atividade turística.

${ }^{5}$ Unidades de Conservação: espaço territorial e seus recursos ambientais, incluindo as águas jurisdicionais, com características naturais relevantes, legalmente instituído pelo Poder Público, com objetivos de conservação e limites definidos, sob regime especial de administração, ao qual se aplicam garantias adequadas de proteção. SNUC (2000)

${ }^{6}$ Dono do Cipó Veraneio, primeiro hotel da região da Serra do Cipó e primeiro prefeito de Santana do Riacho.

${ }^{7}$ Atende grande número de turistas em áreas cênicas, mas já bastante alteradas pela atividade humana. Está associada a áreas com facilidade de acesso, normalmente possuem alguma infraestrutura junto ao atrativo, estão próximas aos locais de maior aglomeração urbana e oferta de serviços, têm o atrativo âncora próximo ao local onde o veículo de transporte chega e caracteriza-se pela grande concentração de pessoas. [...]EPLERWOOD (2007: 36).

${ }^{8}$ Oferece oportunidades de recreação para o mercado "intermediário", numa área de alta qualidade natural, mas não intocada. São áreas com facilidade de acesso (às vezes via estrada de terra), que normalmente não possuem infraestrutura junto ao atrativo e exigem pequena ou média caminhada até o atrativo âncora (ou uso de cavalos, por exemplo). [...]EPLERWOOD (2007: 36).

${ }^{9}$ Áreas com dificuldade de acesso, que normalmente exigem o acompanhamento de um guia ou condutor, não possuem infraestrutura junto ao atrativo, exigem caminhada média ou longa, tem menor concentração de pessoas e são áreas mais conservadas. [...]EPLERWOOD (2007: 36). 
${ }^{10}$ Áreas prístinas e restritas ao acesso de caminhantes ou cavaleiros. Exigem o acompanhamento de guias ou condutores, ou conhecimento profundo da região, incluindo uso de instrumentos de navegação. Estas áreas, normalmente, exigem caminhadas de longo curso ou travessias [...] EPLERWOOD (2007: 36).

Solano de Souza Braga: Universidade Federal de Minas Gerais, Belo Horizonte, MG, Brasil.

E-mail: solanobraga@yahoo.com.br

Link para o currículo Lattes: http://lattes.cnpq.br/3774316982731542

Bernardo Machado Gontijo: Universidade Federal de Minas Gerais, Belo Horizonte, MG, Brasil.

E-mail: bmgontijo@yahoo.com.br

Link para o currículo Lattes: http://lattes.cnpq.br/0882015654292509

Leandro Martins Vieira: Universidade Federal de Minas Gerais, Belo Horizonte, MG, Brasil.

E-mail: leandrovieira@globo.com

Link para o currículo Lattes: http://lattes.cnpq.br/0878691565022717

Data de submissão: 17 de setembro de 2013

Data de recebimento de correções: 21 de janeiro de 2014

Data do aceite: 08 de outubro de 2014

Avaliado anonimamente 